\title{
The Road to Digital and Smart Government in Switzerland
}

\author{
Tobias Mettler
}

\subsection{The Beginnings of E-government In SWITZERLAND}

With the advent of the Internet, low-priced computing devices, and the increasing availability of broadband access in offices and households in the late 1990s, governments all over the world started to discuss how to harness information and communication technology (ICT) to enhance governmental operations and transform public services, and thus their relationship to citizens and businesses. Emulating the preceding radical revolution in banking and commerce, which led to an 'e-everything' phenomenon across all sectors of the economy (Cronin 2000), the new catchword 'e-government' emerged at the turn of the millennium to characterize the onset of digitalizing governments, as well as to describe a new mindset of technology-inspired, forward-looking, and entrepreneurial civil servants.

At about this time, the European Commission (EC) set out the Lisbon Strategy 2000-later succeeded by the Europe 2020 strategy in 2010which formulated the first strategic objectives related to the use of

T. Mettler $(\bowtie)$

IDHEAP, University of Lausanne, Lausanne, Switzerland e-mail: tobias.mettler@unil.ch

(C) The Author(s) 2019

A. Ladner et al. (eds.), Swiss Public Administration, Governance and Public Management, https://doi.org/10.1007/978-3-319-92381-9_10 
innovation in general and ICT in particular for boosting economic progress throughout Europe. This strategic memorandum also paved the way for more detailed e-government action plans-known under different designations over the years, such as the eEurope (Europe Commission 2001), i2010 (Europe Commission 2006), or simply the e-government action plan - the first of which was published only a year later (see Fig. 10.1).

Though not a member of the European Union (EU), the Swiss government's strategic objectives related to e-government have been very much aligned with the EC's strategy. As it was confronted with rapid technological and societal changes at the end of the millennium, the Swiss Federal Council launched a working group in 1997. The goal was to devise a strategic plan and establish priorities with respect to the emerging information society, as well as reallocate the responsibilities for overseeing and coordinating ICT efforts at the federal level.

Based on these working group discussions, the Federal Council mandated a complete reorganization of federal ICT efforts, which led to establishing a new federal steering unit (FITSU) ${ }^{1}$ in 1999. It was responsible for overall ICT program management, and a first federal ICT strategy was set out in 2000. This strategy included preparing two 'lighthouse' projects, an online platform for citizens and businesses known as a 'virtual counter', which went live in $2005,{ }^{2}$ and a multi-site 'e-voting' project. The latter was set up in 2003 in the cantons of Geneva, Neuchâtel, and Zurich to experiment and obtain experience with electronic voting systems, though access to it was limited to Swiss expatriates.

FITSU launched two additional initiatives in 2002. The first was meant to increase interoperability and foster collaboration between the Confederation, the cantons, and the communities. To this end, the nonprofit $\mathrm{eCH}$ association ${ }^{3}$ was founded. Consisting of volunteers from all levels of government, industry, and academia, organized in dedicated chapters or sections, and run on a militia basis - a principle and notion firmly rooted in Swiss identity and mentality-eCH defines technical and non-technical standards and promulgates exemplary process models as well as data to make the implementation of e-government services easier. The second, the eVanti project (Didisheim and Belle 2004) (from the

\footnotetext{
${ }^{1}$ Swiss Confederation, Federal IT Steering Unit, https://www.isb.admin.ch/isb/en/ home.html

${ }^{2}$ Swiss Confederation, https://www.ch.ch/en/

${ }^{3} \mathrm{eCH}$ Association, https://www.ech.ch
} 


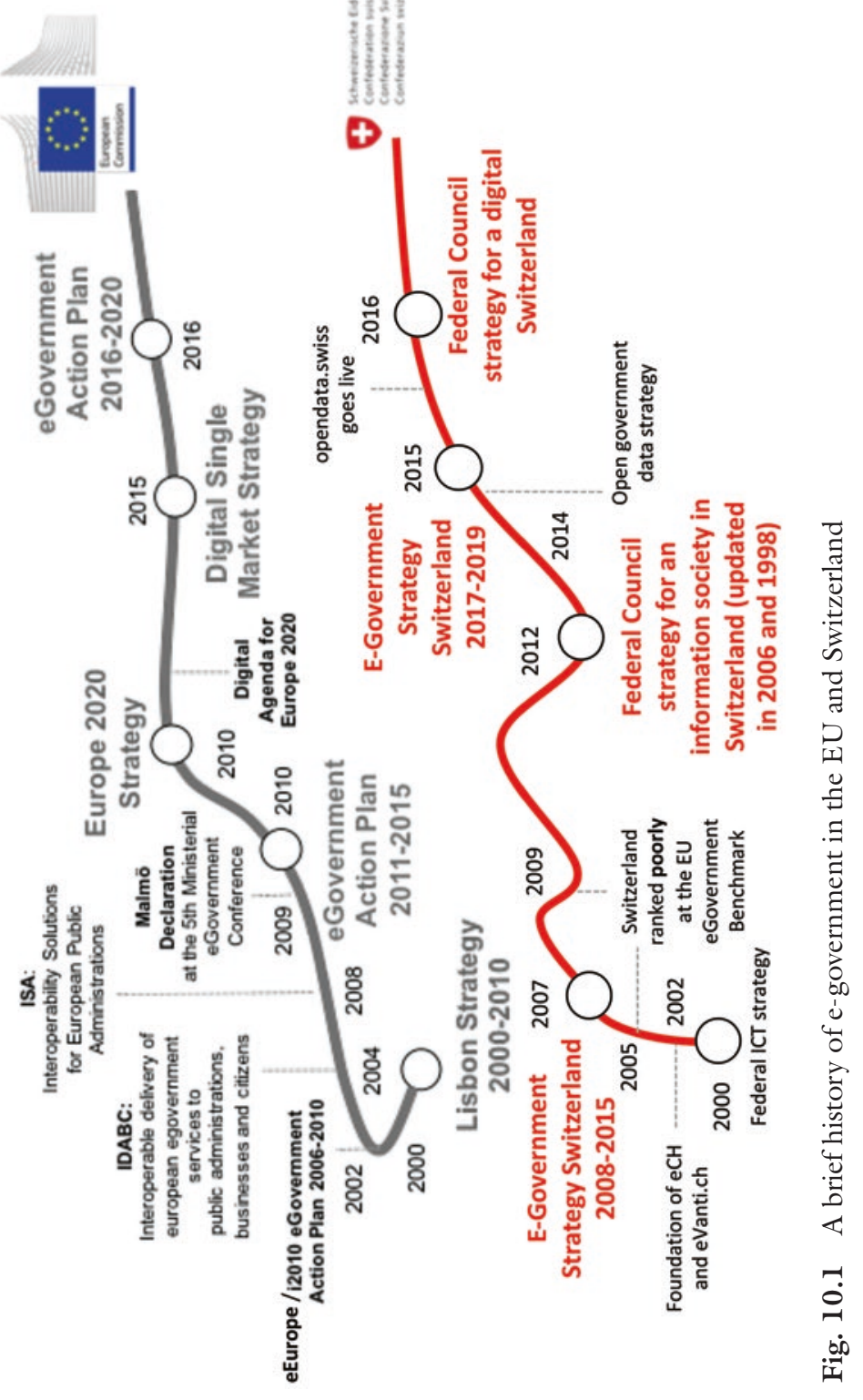


Italian word "avanti", meaning "forward") sought to create a common platform for information exchange between stakeholders, to increase the visibility of successful e-government projects, and to measure how far along existing digital services were. This effort bore some similarity to the Good practice framework for e-government (European Commission 2007) established in 2002 by the EC.

Despite these early efforts and an above-average broadband Internet availability, Switzerland ranked at the bottom of the list of countries assessed in the 2005 EU e-government benchmark. This low ranking led to a reconsideration of strategic objectives several years later and led to crafting a new E-government Strategy Switzerland 2007-2015. This strategy had three goals: first, the most important administrative procedures between businesses and the authorities henceforth should be conducted electronically; second, frequent or complex administrative procedures between citizens and the authorities should be digitalized as well; and lastly, all governmental authorities should modernize their business processes and deal with each other using contemporary electronic channels. To advance the last of these, the Federal Council created a framework agreement on e-government cooperation in 2008 (Federal Council 2007), which clarified the financing, organization, tasks, and responsibilities of the different bodies within the Swiss e-government ecosystem.

While the Swiss authorities at the end of the decade were still occupied with projects such as GEschäftsVERwaltung (GEVER), ${ }^{4}$ meant to re-engineer internal processes and managing the transition from paper-based to electronic styles of working, the EU e-government community-inspired by the targets defined at the Malmö Ministerial Declaration of 2009-had shifted its focus toward a more citizen-centered design, production, and delivery of online services. Accordingly, the EU e-Government Action Plan (2011-2015) (European Commission 2010) emphasized the increased mobility of citizens and their need for empowerment. For instance, the accessibility of public information could be improved by establishing a more user-friendly service delivery through social networking and collaborative tools. Open standards and a service-orientation could further improve the interoperability of existing services and initiate deliberations about the necessary legal and technical preconditions for cross-border services.

Yet because the country neglected to emphasize the central place of the citizen, along with the inward-looking orientation of Swiss governmental

${ }^{4}$ Federal Chancellery, "GEVER”, https://www.bk.admin.ch/bk/de/home/dokumentation/gever-bund.html 
authorities, the Swiss e-government community was dealt a fresh shock in 2009, when Switzerland was again ranked at the bottom end in the EU e-government benchmark.

\subsection{The Transition Years: From E-government to Digital Government}

Confronted with yet another poor ranking in the EU's e-government benchmark, and given that the last major strategy update had been in 2006, the Swiss Federal Council realized that it needed to engage in a major revision and recalibrate its strategic objectives. The updated Strategy of the Federal Council for an Information Society published in early 2012 (Federal Council 2012) included several new areas of activity under subheadings such as Internet governance, high-performance computing, open networks, and the role of ICT as a tool for optimizing energy and resource efficiency.

Three new initiatives were also launched. As a result of an Internet Corporation for Assigned Names and Numbers' decision to abolish most restrictions on the names of generic top-level domains, the first initiative dealt with developing appropriate instruments to preserve Switzerland's public interest in view of the imminent liberalization of the domain name market. On account of the missing citizen-centricity in the previous years, a second priority initiative was to improve and extend barrier-free and equal opportunity access to online information as well as to improve the communications services and transactions of and with the government and the federal administration. The third initiative aimed to enhance the range and availability of statistical data in order to be able to compare the attractiveness of Switzerland with other countries.

As part of this third initiative, the Federal Council devised an open government data (OGD) strategy in 2014, one of whose goals was to increase the availability and reuse of, as well as the access to, public data in machine-readable and open formats. A further goal was to establish an open-data culture in the federal civil service through free, uniform, and understandable terms of use (standardization) and by providing additional information about individual data sets (metadata).

To realize this objective, the Federal Council envisaged building a central infrastructure to replace the pilot portal opendata.admin.ch, which had never been fully operational. It was a major milestone for the Swiss 
opendataswiss is the portal for Swiss open government data (OGO). Here you can downioad Swiss government data free of charge. Enter a term of your choice in the search fleld or click on a categony you are interested in.

Learn more about opendata swiks

\section{2,209 \\ Datasets}

Search datasets.

Q

\section{Categories}

$\begin{array}{lll}\text { Administration } 33 & \text { Geography } 962 & \text { Prices } 15 \\ \text { Agriculture, forestry } 198 & \text { Health } 56 & \text { Public order and security } 26 \\ \text { Construction and housing } 177 & \text { Industry and services } 43 & \text { Social security } 57 \\ \text { Crime, criminal justice } 6 & \text { Legislation } 10 & \text { Statistical basis } 3 \\ \text { Culture, media, information society, sport } & \text { Mobillty and Transport } 273 & \text { Territory and environment } 792 \\ 76 & \text { National economy } 44 & \text { Tourism } 40 \\ \text { Education and science } 200 & \text { Politics } 67 & \text { Trade } 4 \\ \text { Energy } 114 & \text { Population } 263 & \text { Work and income } 50\end{array}$

\section{Get involved}

\section{Data publisher}

Would you like to publish freely available data from your organization on opendata.swiss?

I want to publish data

\section{Data user}

Have you developed an application using data from opendata.swiss? Please contact us.

I have developed an application

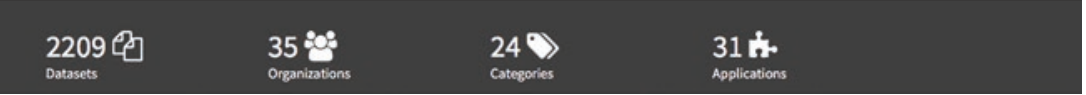

Fig. 10.2 Opendata.swiss—Switzerland's open government data portal

e-government community when the new OGD portal opendata.swiss was launched on February 2016. It held about 500 unique datasets originating from 17 different public organizations, including the Swiss Federal Railways and the Federal Roads Office, and it covers a wide range of topics in the Swiss public sector (see Fig. 10.2). It is hosted and maintained by the Swiss Federal Archive ${ }^{5}$.

\footnotetext{
${ }^{5}$ Swiss Federal Archive, https://opendata.swiss/
} 


\subsection{The Vision for a New Digital Switzerland}

In many ways, 2015 marked an important turning point for the European e-government community. Jean-Claude Junker's election as President of the EC in late 2014 ushered in a new orientation to, and prioritization of, digital initiatives. The previous Europe 2020 strategy had focused strongly on the transition to a digital society; the new Digital Single Market Strategy envisioned establishing a businessfriendly environment for the European economy with the goal of fostering innovation and creating hundreds of new jobs in the technology and service sector. There are plans to emend the rules for online crossborder sales, improve cross-border parcel delivery, abolish geo-blocking, reform European copyright law, review the rules for audiovisual media, assess the role of big corporate online platforms, define priorities for e-government standards and interoperability, and to address issues of ownership, usability, and access to large data collections (European Commission 2015).

In keeping with this shift in European e-government priorities, there is now a new Federal Council strategy for a digital Switzerland (Federal Office of Communictions 2016) and a redefined Swiss e-Government Strategy 2017-2019 (Swiss Confederation 2016).

The goals of the Federal Council's new strategy include the following:

- Improving the general conditions of Switzerland's digital economy and monitoring developments, anticipating challenges and addressing regulatory issues related to the sharing economy

- Defining coherent and future-oriented national data policies and further developing the national data infrastructure based on the existing OGD platform

- Extending access to high-speed broadband to all Swiss municipalities by 2020

- Increasing the use of innovative technology to reduce energy consumption and $\mathrm{CO}_{2}$ emissions as well as enhancing the attractiveness of domestic online trade

- Ensuring multiple uses of different solutions and implementing a secure digital identity to create seamless interactions with civil society and the private sector 
- Introducing electronic patient files to improve both quality and efficiency in health care, facilitating health reforms, and enhancing information exchange with European health organizations

- Expanding the use of ICT for democratic decision-making and opinion-formation

- Increasing the availability of new opportunities for education and training as well as intensifying Switzerland's role in research and innovation related to the digital society and the digital economy

- Establishing digital cultural production and providing universal access to cultural heritage facilitated by the Internet

As before, and in keeping with the Federal Council's strategy and with the strategic objective to support the innovative potential of the Swiss economy, as well as strengthen standardization and the economic viability of governmental digital initiatives, the Swiss e-Government Strategy 2017-2019 also identified a number of 'lighthouse' projects ${ }^{6}$ that are meant to have a short-term impact and pave the way for a new digital Switzerland. The Swiss Confederation, cantons, and communities agree to collaborate on realizing the following goals and projects:

- A joint organization to be established by 2018 for procuring, operating, and maintaining e-government solutions

- Having a seamless electronic change of residence registration system throughout Switzerland by the end of 2018

- Establishing a uniform registration procedure for e-government services on various government portals by 2019

- Integrating the ten electronic public services most frequently requested by the general public and by businesses into the national e-government portals by the end of 2019

- Introducing an electronic identity (eID) that is valid nationally and internationally, as well as assigning data to a specific person as part of the electronic exchange between information systems to be established by 2019

- Developing an electronic transmission procedure for reporting value added tax (VAT), to be effective by 2019

- Extending electronic voting to more voters, with the aim of seeing two-thirds of the cantons use electronic voting by 2019

\footnotetext{
${ }^{6}$ Swiss Confederation, "Strategic projects and services", https://www.egovernment.ch/ en/umsetzung/schwerpunktplan/
} 


\subsection{The Path Yet to Go to Create a Smart GOVERNMENT...}

Aside from the actions coordinated from the top that have been noted, there are many promising bottom-up developments at the local and cantonal levels, including hospitals or universities that have experimented with new service delivery models facilitated by the Internet of Things (IoT) (Wortmann and Flüchter 2015). These 'smart government initiatives' use emerging technologies such as sensor-based systems or artificial intelligence in conjunction with various social innovation strategies. The goal is to improve a public authority's understanding of its community and constituency in order to enhance the accuracy of their decision-making and response efficiency, not at least in case there are unexpected or seriously adverse events (Gil-Garcia et al. 2014). In doing so, physical components and devices (e.g. intelligent energy controllers, parking lot systems, web cams, motion sensors) are connected with extant public digital platforms and private infrastructures, creating unprecedented ways for both passive and active interaction between a public administration and citizens (see Fig. 10.3).

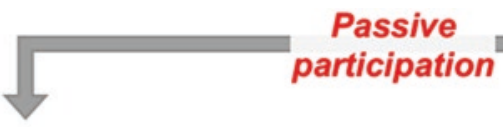

Public

infrastructure

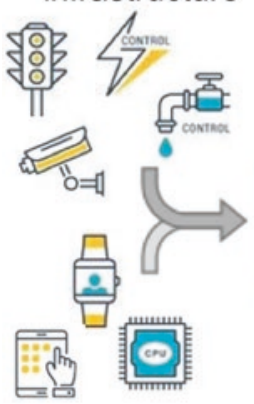

Private

infrastructure

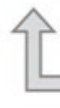

Big Data
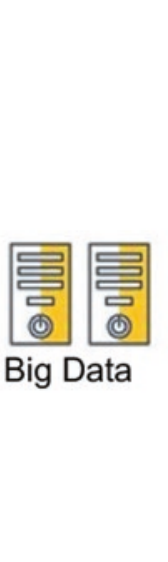

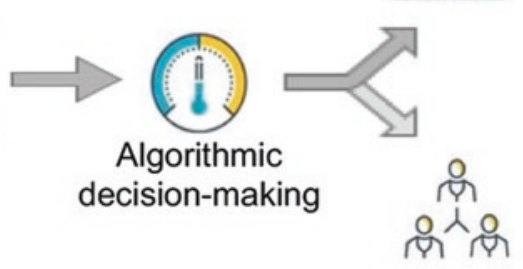

Personalized

feedback

\section{Active participation}

Fig. 10.3 Smart government lifecycle Guenduez et al. (2017) 
Thus, the city of Lausanne is developing a centralized management system that is able to control all 14,000 of its street lights. The city of St. Gallen has recently implemented several smart appliances, including intelligent power-charging stations which can inform electric car owners where to find free spots for charging their batteries in the city or sensor-based waste containers that can notify citizens and municipal garbage collectors alike about how full the containers currently are. Based on combining sensor data with open data, the city of Zurich has introduced online services and mobile apps such as AirCHeck (which issues real-time information about the city's air quality) and ParkenDD (which shows where the free parking spaces are in the city). Given that smart appliances and services frequently raise privacy concerns, at Lausanne's Swiss Graduate School of Public Administration (IDHEAP) we are also experimenting with privacyaware alternatives to $24 \times 7$ monitoring, including in the search and rescue of people with disabilities ${ }^{7}$.

Such examples are only the first steps toward smarter governance, sustainability, and increased citizen experience. But there is still a long way to go until smart government projects can create value beyond the local habitat which nurtured them.

\subsection{CONCLusion}

Digital initiatives in Switzerland involve various stakeholders at different government levels, but unlike countries which are ruled from the center, Switzerland's approach to digitalization has required finding political consensus. That has both advantages and disadvantages.

On the one hand, important top-down decisions concerning the basic direction and prioritization of digitalization endeavors are more broadly supported in this consensus-oriented polity, resulting in targeted and collaborative efforts among and across different levels of government. Moreover, positive and dynamic change has resulted from bottom-up initiatives driven by local communities, cities, non-profit organizations, and businesses. This combined approach-coordinated political and policy actions together with grassroots movements-is characteristic of Switzerland and is a continual driver of innovation as well as modernization.

On the other hand, Switzerland's decentral form of governance significantly increases the complexity of the country's digital transformation and

${ }^{7}$ T. Mettler, “iCare Research project website”, http://unil.ch/icare/ 
ultimately negatively influences the pace at which emerging technologies are introduced. To a certain extent, it also means tolerating inefficiencies, as when various rival systems co-exist. In this context, the Swiss e-government community needs to find more efficient and effective ways of overcoming issues concerning legal and organizational boundaries. Suitable ways to align top-down and bottom-up initiatives or competing innovation strategies will also need to be developed.

From an international perspective, it would be nice to see a more layered, contextual monitoring and benchmarking of technological, political, economic, and social aspects of the country's digital transformation. Many attempts to somehow 'quantify' the effects of digitalization favor centralist countries, often disregarding the inequalities or ignoring the 'digital divide', which separates regions, urban from rural areas, differing cultures, or population segments in the country. In this regard, Switzerland is an interesting case, as digitalization is promoted both centrally and locally, yet with a view to balance needs, power, and responsibilities among the many distinct actors in Swiss society.

\section{REFERENCES}

Cronin, M. J. (2000). Unchained value: The new logic of digital business. Boston: Harvard Business School Press.

Didisheim, J.-J. \& Belle, L. (2004). eVanti.ch - eine Initiative zur Förderung des eGovernments. http://www.visit.isb.admin.ch/2004/programm/referate/07_ didisheim_belle.pdf

European Commission. (2001). eEurope 2002. http://eur-lex.europa.eu/legalcontent/EN/TXT/?uri=uriserv:124226a. Accessed 26 Mar 2018.

European Commission. (2006). i2010 eGovernment Action Plan. http://eur-lex. europa.eu/legal-content/EN/TXT/?uri=URISERV\%3Al24226j. Accessed 26 Mar 2018.

European Commission. (2007). Good practice framework for eGovernment Final report. https://bookshop.europa.eu/en/good-practice-framework-foregovernment-pbKK0414484/

European Commission. (2010). European eGovernment action plan 2011-2015. http://eur-lex.europa.eu/legal-content/EN/TXT/?uri=CELEX\% 3A52010DC0743

European Commission. (2015). A digital single market strategy for Europe. http://eur-lex.europa.eu/legal-content/EN/TXT/?qid=1447773803386\& uri $=$ CELEX\%3A52015DC0192 
Federal Council. (2007). Framework agreement under public law on e-government cooperation in Switzerland. https://www.admin.ch/opc/de/federalgazette/2008/3391.pdf

Federal Council. (2012). Federal strategy for Switzerland's digital future. https:// www.admin.ch/gov/en/start/dokumentation/medienmitteilungen.msgid-43694.html

Federal Office of Communictions. (2016). Federal council strategy for a digital Switzerland. https://www.bakom.admin.ch/bakom/en/homepage/digitalswitzerland-and-internet/strategie-digitale-schweiz/strategy.html

Gil-Garcia, J. R., Helbig, N., \& Ojo, A. (2014). Being smart: Emerging technologies and innovation in the public sector. Government Information Quarterly, 31, Il-I8.

Guenduez, A. A., Mettler, T., \& Schedler, K. (2017). Smart Government Partizipation und Empowerment der Bürger im Zeitalter von Big Data und personalisierter Algorithmen. HMD - Praxis der Wirtschaftsinformatik, $54,477-487$.

Swiss Confederation. (2016). eGovernment Strategy 2017-2019. https://www. egovernment.ch/de/umsetzung/schwerpunktplanl

Wortmann, F., \& Flüchter, K. (2015). Internet of things: Technology and value added. Business o Information Systems Engineering, 57(3), 221-224.

Open Access This chapter is licensed under the terms of the Creative Commons Attribution 4.0 International License (http://creativecommons.org/licenses/ by $/ 4.0 /$ ), which permits use, sharing, adaptation, distribution and reproduction in any medium or format, as long as you give appropriate credit to the original author(s) and the source, provide a link to the Creative Commons license and indicate if changes were made.

The images or other third party material in this chapter are included in the chapter's Creative Commons license, unless indicated otherwise in a credit line to the material. If material is not included in the chapter's Creative Commons license and your intended use is not permitted by statutory regulation or exceeds the permitted use, you will need to obtain permission directly from the copyright holder.

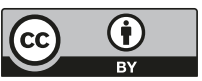

